\title{
Efficiency of remote sensing tools for post-fire management along a climatic gradient
}

\author{
José Manuel Fernández-Guisuraga*, Leonor Calvo, Víctor Fernández-García, Elena Marcos-Porras, \\ Ángela Taboada, Susana Suárez-Seoane \\ Biodiversity and Environmental Management Dpt., Faculty of Biological and Environmental Sciences, University of León, 24071 León, Spain
}

\section{A R T I CLE INFO}

\section{Keywords:}

Atlantic-Transition-Mediterranean climatic gradient

Bayesian Model Averaging (BMA)

Image texture

Model extrapolation

Model generality

Model inference

Model transferability

Pinus pinaster

Vegetation cover

WorldView-2

\begin{abstract}
A B S T R A C T
Forest managers require reliable tools to evaluate post-fire recovery across different geographic/climatic contexts and define management actions at the landscape scale, which might be highly resource-consuming in terms of data collection. In this sense, remote sensing techniques allow for gathering environmental data over large areas with low collection effort. We aim to assess the applicability of remote sensing tools in post-fire management within and across three mega-fires that occurred in pine fire-prone ecosystems located along an Atlantic-Transition-Mediterranean climatic gradient. Four years after the wildfires, we established $1202 \times 2 \mathrm{~m}$ plots in each mega-fire site, where we evaluated: (1) density of pine seedlings, (2) percentage of woody species cover and (3) percentage of dead plant material cover. These variables were modeled following a Bayesian Model Averaging approach on the basis of spectral indices and texture features derived from WorldView-2 satellite imagery at $2 \mathrm{~m}$ spatial resolution. We assessed model interpolation and transferability within each mega-fire, as well as model extrapolation between mega-fires along the climatic gradient. Texture features were the predictors that contributed most in all cases. The woody species cover model had the best performance regarding spatial interpolation and transferability within the three study sites, with predictive errors lower than $25 \%$ for the two approaches. Model extrapolation between the Transition and Mediterranean sites had low levels of error (from $6 \%$ to $19 \%$ ) for the three field variables, because the landscape in these areas is similar in structure and function and, therefore, in spectral characteristics. However, model extrapolation from the Atlantic site achieved the weakest results (error higher than 30\%), due to the large ecological differences between this particular site and the others. This study demonstrates the potential of fine-grained satellite imagery for land managers to conduct post-fire recovery studies with a high degree of generality across different geographic/climatic contexts.
\end{abstract}

\section{Introduction}

Forest fires are disturbances associated with significant social, economic and environmental impacts (Nunes et al., 2016; Pinto et al., 2017; Hong et al., 2018). In fire-prone forest ecosystems of the Mediterranean Basin, many authors have identified an increase in fire regime parameters, such as recurrence and severity, in large forest fires (Pausas and Keely, 2009; Ferreira-Leite et al., 2011; Bento-Gonçalves et al., 2012; Quintano et al., 2015), mainly as a consequence of land use change (Pereg et al., 2018) and global warming (Doblas-Miranda et al., 2017). In these ecosystems, vegetation recovery depends on the spatial variation of landscape components, fire regime parameters and climatic characteristics (Beaty and Taylor, 2001; Tessler et al., 2016). Direct impacts of forest fires include the removal of the vegetation cover
(Shakesby, 2011), which may intensify soil erosion processes (Perrault et al., 2017; Pereira et al., 2018) and sediment yield in vulnerable areas (Esposito et al., 2017). Moreover, wildfires may seriously affect the regeneration of the dominant tree species, mainly depending on the fire regime (Fernandes and Rigolot, 2007; Calvo et al., 2008; Fernández-García et al., 2018).

In fire-prone pine ecosystems, the assessment of understory and forest canopy recovery in the short term (less than 5 years; Meng et al., 2018) has a substantial implication in post-fire management strategies (García-Morote et al., 2017; Meng et al., 2018) aimed at reducing the risk of suffering erosive processes across large burned areas (Pausas et al., 2008). Therefore, forest managers require reliable tools, as post-fire spatially explicit models, to evaluate vegetation recovery at the landscape scale (Mansourian et al., 2005).

\footnotetext{
* Corresponding author.

Email address: jofeg@unileon.es (J.M. Fernández-Guisuraga)
} 
The evaluation of the applicability of recovery models developed at particular sites to other geographic/climatic contexts could provide a valuable tool in post-fire management decision-making (Roach et al., 2017). This would allow for exploiting data collected in other wildfire locations (Latif et al., 2016), reducing data collection efforts in the area of interest. Nevertheless, the applicability of post-fire recovery models between burned sites remains a challenge because post-fire vegetation structure and composition is highly influenced by climatic factors across geographical gradients (Tao et al., 2013; Fernández-García et al., 2018), primarily precipitation and temperature (Sevegnani et al., 2016), as well as fire regime properties (Bond et al., 2005; Sevegnani et al., 2016).

Different problems must be faced in the evaluation of model applicability across different geographic/climatic contexts, such as: (i) Site-specific indirect relationships between response variables and predictors based strictly on correlation rather than on an ecological basis (Austin, 2002; Sundblad et al., 2009; Wenger and Olden, 2012), which together with an excessive parameterization of the model, could lead to a decrease in model generality (Wenger et al., 2011). (ii) Non-stationarity of the response-predictors relationships (Osborne et al., 2007; Suárez-Seoane et al., 2014), which are not constant across space (Brunsdon et al., 1996). (iii) The spatial heterogeneity of ecological relationships, which may restrict the transfer of relationships between sites (Wenger and Olden, 2012). In the case of burned sites across a climatic gradient, changes in vegetation structure can be associated to non-stationary responses between the field-sampled variables and the considered predictors, which may limit model applicability between sites and, therefore, its implications in post-fire management.

The applicability of recovery models to other contexts can be assessed in terms of spatial interpolation (applying model predictions to areas that spatially overlap with the calibration dataset within the study area), transferability (applying model predictions to areas that do not spatially overlap with the calibration dataset, but with similar environmental features in the study area) and extrapolation (applying model predictions to other study sites with different environmental characteristics) (Peterson et al., 2007; Jiménez-Alfaro et al., 2018).

Post-fire monitoring of large burned areas based on field work is very informative, but highly time and labor intensive (Chuvieco and Kasischke, 2007). In this sense, remote-sensing based techniques (RST) are considered an essential tool for monitoring ecosystem recovery after fire (Lozano et al., 2012; Mitri and Gitas, 2013; Fernández-Manso et al., 2016). Very high spatial (VHS) resolution imagery provided by spaceborne sensors, such as WorldView-2, has been used to evaluate post-fire recovery in heterogeneous burned environments (i.e. Jung et al., 2013; Mitri and Gitas, 2013; Chu et al., 2016; Meng et al., 2018). In fact, the fine pattern of variability observed in the vegetation after heterogeneous fires cannot be captured with low spatial resolution sensors (Meng et al., 2017). Several studies, such as that conducted by Chu et al. (2016), showed the importance of using spectral indices derived from VHS sensors as predictors of vegetation recovery after a fire disturbance. Moreover, Viedma et al. (2012) proposed the use of satellite imagery texture analysis to monitor post-fire vegetation structure. In this sense, Gu et al. (2013) demonstrated that image texture alone or in combination with spectral indices derived from VHS satellite imagery improved the estimation of the vegetation structure in heterogeneous burned areas. The vertical and horizontal structure of vegetation in these areas influences spectral reflectance and, therefore, the performance of spectral indices and texture features derived from satellite imagery (Thenkabail et al., 2011). Particularly, canopy reflectance varies with leaf area (Buchhorn et al., 2013; Zhu et al., 2013), pigment composition (Xiao and Moody, 2008), vegetation biomass and height (Buchhorn, 2014; Thenkabail et al., 2011), as well as with the cover of different plant functional types and the total vegetation cover (Buchhorn et al., 2013; Thenkabail et al., 2011).
The applicability of remote sensing products across different climatic conditions has been evaluated in the assessment of burn severity (Fernández-García et al., 2018), prediction of savanna vegetation variables such as shrub and tree density and cover (Tsalyuk et al., 2017), estimation of tropical forest biomass (Foody et al., 2003; Cutler et al., 2012) or prediction of leaf area index in pine forests (Sumnall et al., 2016). However, to our knowledge, there are no studies addressing the applicability of post-fire recovery models of large burned areas across climatic gradients.

In this study, we aim to assess the applicability for land management at short term of post-fire recovery models based on remote sensing tools in fire-prone pine ecosystems located across an Atlantic-Transition-Mediterranean climatic gradient. Specifically, we: (1) generate a remote sensing derived tool for evaluating post-fire vegetation recovery in each study site located throughout the climatic gradient, comparing the role of spectral indices and textural features derived from fine-grained satellite imagery; (2) evaluate the spatial interpolation of the recovery models within each study site of the climatic gradient; (3) assess model transferability between geographically different subsets of each study site; and (4) check a more challenging scenario in which we extrapolate the recovery models built on one study site to predict recovery in the other sites across the climatic gradient. We hypothesized that texture features derived from satellite imagery will provide a greater contribution than spectral features in the recovery models given the ground spatial heterogeneity of fire-prone ecosystems (Schoennagel et al., 2008). We also expect that spatial interpolation would perform better than spatial transferability, spatial extrapolation being the approach with the poorest performance due to strong environmental variation along the climatic gradient (Thuiller et al., 2004; Jiménez-Alfaro et al., 2018). Finally, we hypothesized that spatial extrapolation would achieve the best results when applied from the extremes of the climatic gradient (Atlantic and Mediterranean climatic conditions) towards the center of the gradient (Transition climatic conditions). We expect this behavior because the range of environmental conditions would be narrower in the center than in the extremes of the climatic gradient. Thus, the truncation in the model calibration data would be greater in the Transition climatic conditions (Hernandez et al., 2006; Suárez-Seoane et al., 2014).

\section{Materials and methods}

\subsection{Study area}

We selected three megafires along an Atlantic-Transition-Mediterranean climatic gradient within Spain (Fig. 1).

The Atlantic study site is located within the perimeter of a megafire that occurred in September of 2013, which burned 2,523 ha mostly covered by Pinus pinaster forest. The site elevation ranges from 0 to $628 \mathrm{~m}$ above sea level (m.a.s.l.) and has an abrupt morphology due to the contrast between the granitic relief and the coastal plain. Soils are acidic given the granitic nature of the lithology (Rodríguez-Lado, 2012). The climate is Atlantic, with an annual average rainfall of $1655 \mathrm{~mm}$ and an annual average temperature of $13^{\circ} \mathrm{C}$, without summer drought (Ninyerola et al., 2005). Vegetation cover following fire mainly consists of Pinus pinaster and Eucalyptus globulus regeneration stands, the understory community mainly being composed by Ulex europaeus and Rubus sp.

The Transition site is a mega-fire that occurred in August 2012. The burned surface was 11,602 ha, predominantly covered by a Pinus pinaster forest. The relief is heterogeneous, with wide valleys, prominent crests and sedimentary plains. Soils are acidic, originating from siliceous lithologies (Calvo et al., 2008; Fernández-García et al., 2018). The elevation ranges from 836 to 1499 m.a.s.l. This area has transi- 


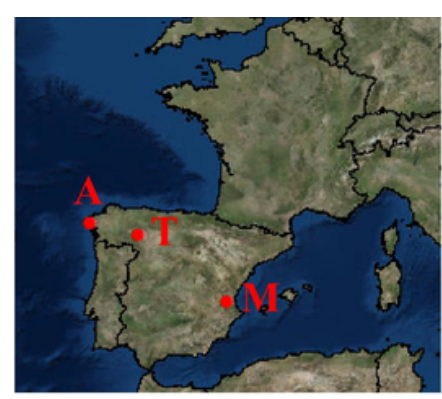

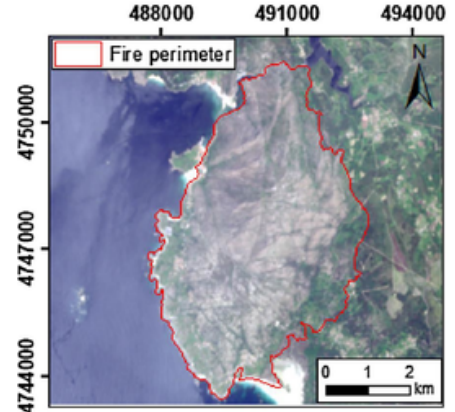

Atlantic site (A)

September 2013; 2,523 ha

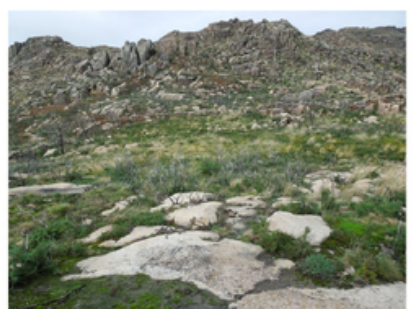

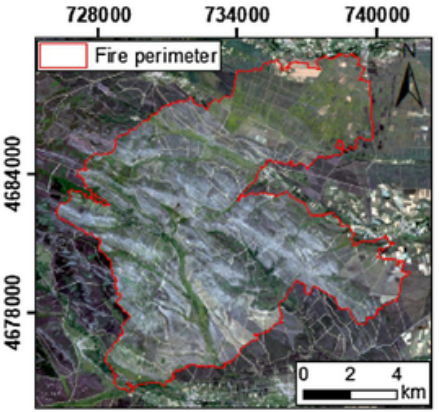

Transition site (T)

August 2012; 11,602 ha

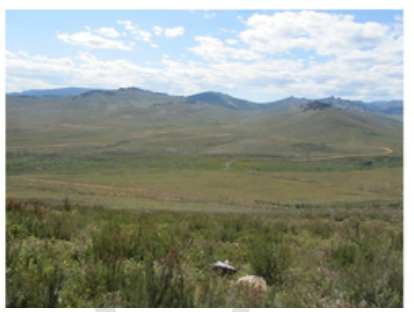

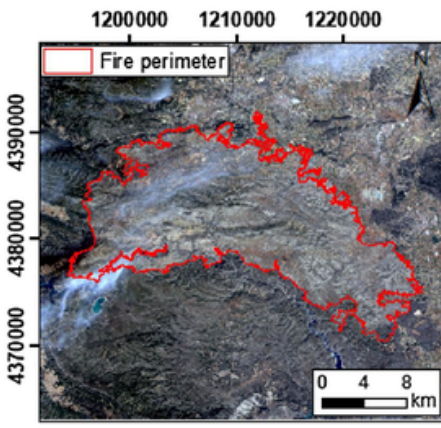

Mediterranean site (M)

June $2012 ; 29,752$ ha

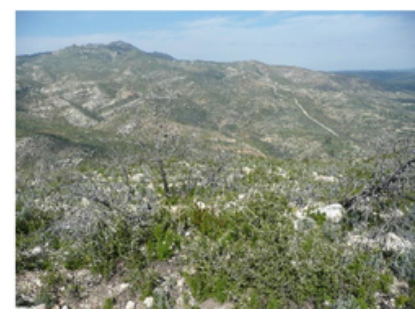

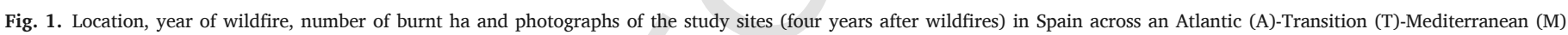
climatic gradient.

tional climatic conditions between Atlantic and Mediterranean, with average annual rainfall of $640 \mathrm{~mm}$ and an average annual temperature of $10^{\circ} \mathrm{C}$, presenting two months of summer drought (Ninyerola et al., 2005). Post-fire vegetation cover is constituted by Pinus pinaster and Quercus pyrenaica regeneration stands and Halimium alyssoides, Pterospartum tridentatum and Erica australis in the understory layer.

The Mediterranean site is a megafire of 29,752 ha that occurred in June 2012. Pre-fire and post-fire vegetation is dominated by Pinus pinaster and Pinus halepensis regeneration stands, and Quercus coccifera, Ulex parviflorus and Rosmarinus officinalis shrublands. The study site has steep slopes and altitude ranges between 114 and 995 m.a.s.l. Soils are basic and the dominant lithological material is of sedimentary origin (CEAM, 2012). Average annual rainfall is $582 \mathrm{~mm}$ and the average annual temperature is $16^{\circ} \mathrm{C}$, with three months of summer drought (Ninyerola et al., 2005), corresponding to a Mediterranean climate.

\subsection{Field data}

Four years after the fire, a set of $1202 \times 2 \mathrm{~m}$ field plots (equal to WorldView-2 spatial resolution) was randomly established in each study site. In each plot, we sampled three variables quantifying vegetation recovery at both population (dominant tree species) and community (understory) levels: density of pine seedlings, woody species cover and dead plant material cover. Cover variables were quantified as cover percentage using a visual method of estimation (Calvo et al., 2008). These three variables are key indicators for land management actions in areas affected by large forest fires (Solans-Vila and Barbosa,
2010; Veraverbeke et al., 2012; Fernández-Manso et al., 2016), as they allow for identifying priority areas of high susceptibility to erosion processes (Schmeer et al., 2018) and areas where afforestation strategies should be implemented. In specific, the accumulation of dead plant material after a forest fire can increase flammability (Whelan, 1995; Chuvieco et al., 2004; Hart et al., 2015) and, therefore, the risk of new fire events (Log et al., 2017). Each field plot was georeferenced with a high-accuracy GPS receiver (Spectra Precision MobileMapper 20) in post-processing mode. Registration accuracy was better than $0.50 \mathrm{~m}$ in terms of root mean square error $\left(\mathrm{RMSE}_{\mathrm{X}, \mathrm{Y}}\right)$.

\subsection{WorldView-2 imagery data}

The WorldView-2 images were acquired on June 15th, 2016, at 11:12:48 UTC for the Mediterranean site, June 23rd, 2016, at 11:38:02 UTC for the Transition site and June 18th June 2017, at 11:53:54 UTC for the Atlantic site. Cloud cover was lower than $0.5 \%$ in the three images. The spatial resolution of the WorldView-2 multispectral sensor is $2 \mathrm{~m}$. This sensor captures data over eight spectral bands (DigitalGlobe, 2010): B1) coastal blue $(400-450 \mathrm{~nm}), \mathrm{B} 2)$ blue $(450-510 \mathrm{~nm}), \mathrm{B} 3)$ green (510-580 nm), B4) yellow (585-625 nm), B5) red (630-690 nm), B6) red edge (705-745 nm), B7) NIR1 (770-895 nm) and B8) NIR2 (860-1040 nm). Raw imagery was orthorectified with rational polynomial coefficients, a digital elevation model with an accuracy better than $20 \mathrm{~cm}$ in terms of $\mathrm{RMSE}_{\mathrm{Z}}$ and, at least, 100 ground control points evenly distributed and extracted from aerial orthophotos of the Spanish National Plan of Aerial Orthophotography (PNOA). The atmospheric 
correction of the imagery was conducted using the FLAASH algorithm (Berk et al., 1999; Matthew et al., 2003), which allowed a bottom of atmosphere (BOA) reflectance product to be obtained. Data for atmospheric correction, such as visibility and column water vapor amount, were obtained from the State Meteorology Agency of Spain (AEMET).

Two types of products were extracted from the WorldView-2 BOA reflectance imagery as predictors of vegetation recovery: spectral indices and texture features. The chosen spectral indices (Table 1A) have proven to be useful in the estimation of forest and shrubland structural parameters (Shamsoddini et al., 2013; Mitchell et al., 2015; Liu et al., 2017). Texture features comprised two 2nd-order textures (mean and variance) calculated from bands 1, 3, 6 and 7 of the WorldView-2 imagery (Table 1B). These texture measures and bands were chosen based on previous research carried out in fire-prone pine ecosystems (Fernández-Guisuraga et al., unpublished results). The 2nd-order textures were computed using the Gray Level Co-Occurrence Matrix (GLCM) (Haralick et al., 1973). We selected a moving window of $3 \times 3$ pixels to capture the high landscape post-fire heterogeneity in our study areas (Chen et al., 2004). Textures were calculated from the four different window orientations $\left(0^{\circ}, 45^{\circ}, 90^{\circ}\right.$ and $\left.135^{\circ}\right)$ and then averaged to obtain directionally invariant texture measures (Zhang and Xie, 2012).

Predictors' values were extracted for the pixels matching the field plots where population and community variables were sampled.

\subsection{Statistical framework}

Vegetation recovery was modeled in each study site by means of Bayesian Model Averaging (BMA; Raftery et al., 1997; Hoeting et al., 1999) to account for uncertainty in the model selection process (Zhao et al., 2013). Response variables were those sampled in the field plots and predictors were the spectral indices and texture features, both derived from WorldView-2 imagery. Several authors, such as Liang et al. (2008), have demonstrated that BMA improves the predictive capacity of other statistical techniques. Zellner's g prior (Zellner, 1986) for model coefficients was used along with the g-BRIC hyperparameter (Fernández et al., 2001), which offers the best predictive performance (Fernández et al., 2001) and provides the most parsimonious models (Liang et al., 2008). The entire model space was fully enumerated by iterating all possible predictor combinations ( $2^{12}$ iterations). A grid was plotted indicating the signs and inclusion of coefficients versus posterior inclusion probabilities (PIP) for the entire model space. Predictors with PIP $>0.5$ are considered to be highly correlated to the response variable (Barbieri and Berger, 2003; Eicher et al., 2009).

Table 1

Spectral indices (A) and textural features (B) predictors derived from the WorldView-2 BOA reflectance imagery. $p(i, j)$ represents the value in $i, j$ cell of GLCM and $N$ is the number of gray levels. ARI and TCARI formulas were adapted to WorldView-2 bands that span within acceptable wavelength ranges of the equations presented in the literature.

\begin{tabular}{|c|c|c|}
\hline (A) Index & Formula & Reference \\
\hline $\begin{array}{l}\text { Anthocyanin Reflectance Index } \\
2 \text { (ARI) }\end{array}$ & $\mathrm{B} 7[(1 / \mathrm{B} 3)-(1 / \mathrm{B} 6)]$ & $\begin{array}{l}\text { Gitelson et al. } \\
\text { (2001) }\end{array}$ \\
\hline Burnt Area Index (BAI) & $1 /\left[(0.1-\mathrm{B} 5)^{2}+(0.06-\mathrm{B} 8)^{2}\right]$ & $\begin{array}{l}\text { Chuvieco et al. } \\
\text { (2002) }\end{array}$ \\
\hline $\begin{array}{l}\text { Normalized Difference } \\
\text { Vegetation Index (NDVI) }\end{array}$ & $(\mathrm{B} 7-\mathrm{B} 5) /(\mathrm{B} 7+\mathrm{B} 5)$ & Rouse et al. (1973) \\
\hline $\begin{array}{l}\text { Transformed Chlorophyll } \\
\text { Absorption Reflectance Index } \\
\text { (TCARI) }\end{array}$ & $\begin{array}{l}3[(\mathrm{~B} 6-\mathrm{B} 5)-0.2(\mathrm{~B} 6-\mathrm{B} 3)(\mathrm{B} 6 / \\
\mathrm{B} 5)]\end{array}$ & $\begin{array}{l}\text { Haboudane et al. } \\
\text { (2004) }\end{array}$ \\
\hline (B) Texture & Formula & Reference \\
\hline Local mean of GLCM window & $\sum_{i, j=0}^{N-1} i p(i, j)=\mu$ & $\begin{array}{l}\text { Haralick et al. } \\
\text { (1973)Pu and } \\
\text { Cheng (2015) }\end{array}$ \\
\hline $\begin{array}{l}\text { Local variance of GLCM } \\
\text { window }\end{array}$ & $\sum_{i, j=0}^{N-1} p(i, j)(i-\mu)^{2}$ & $\begin{array}{l}\text { Haralick et al. } \\
\text { (1973)Pu and } \\
\text { Cheng (2015) }\end{array}$ \\
\hline
\end{tabular}

The predictive capacity of the models was computed as the root mean square error (RMSE, eq.1) normalized using the maximum $\left(y_{\max }\right)$ and minimum $\left(y_{\min }\right)$ value of observations for each response variable (nRMSE, eq.2).

$$
\begin{aligned}
& R M S E=\sqrt{\frac{1}{n} \sum_{i=1}^{n}\left(\AA_{i}-y_{i}\right)^{2}} \\
& n R M S E=\frac{R M S E}{y_{\max }-y_{\min }} \times 100
\end{aligned}
$$

Model interpolation was evaluated within each study site by randomly partitioning the field data into a training subset ( $2 / 3$ of data) to calibrate the models and a validation subset ( $1 / 3$ of the data) to assess the model performance. Transferability within study sites was tested by partitioning the data into four geographic quadrants to avoid an arbitrary split of the data (Osborne and Suárez-Seoane, 2002). Data comprised within 3 out of 4 quadrants were used for training purposes and data from the remaining quadrant for validation in an iterative procedure, performing a "geographic 4-fold cross-validation" (Osborne and Suárez-Seoane, 2002; Radosavljevic and Anderson, 2014; Jiménez-Alfaro et al., 2018). The extrapolation among study sites was evaluated by applying the model equation derived from the training subset of a study site to the full dataset of the other study sites in an iterative procedure (Fig. 2). To evaluate the extrapolation performance, bivariate Pearson correlations were computed between the predicted values achieved by model extrapolation and the observed field values in each study site.

All statistical analyses were performed using R (R Core Team, 2017) using the BMS package (Zeugner and Feldkircher, 2015).

\section{Results}

3.1. Post-fire vegetation recovery tools: Importance of spectral and textural features

Textural features were, for the three response variables, the most contributing predictors in the recovery models along the climatic gradient. Band 6 (red edge) and band 7 (NIR-1) textures presented a PIP > 0.90 in five out of nine recovery models (Fig. 3).

Spectral indices (ARI and NDVI) and texture features (variance of band 3 and 7) were closely related (PIP > 0.5) to pine seedling density in the Transition site. The probability of each predictor being chosen for this response variable was lower than 0.40 in the Atlantic and Mediterranean sites. Woody species cover was strongly related with mean texture features in each study site across the climatic gradient, mainly with the mean of band 6 (PIP > 0.98) in the Atlantic and Mediterranean sites. The estimation of dead plant material cover was associated to the mean and variance of band 7 in the three study sites.

\subsection{Interpolation, transferability and extrapolation}

The spatial interpolation analysis carried out across the climatic gradient (Table 2) showed the best performance, in terms of nRMSE, for the case of the woody species cover model. The highest error was found in the Atlantic site for the three recovery variables.

Transferability analysis (Table 2) exhibited a worse predictive performance than spatial interpolation for each study site and recovery variable. The most notable differences in terms of nRMSE between model interpolation and transferability approaches were found for the Mediterranean site. The best performing transferability analysis was achieved for the woody species cover in the three sites across the climatic gradient. 


\section{Calibration data Validation data}

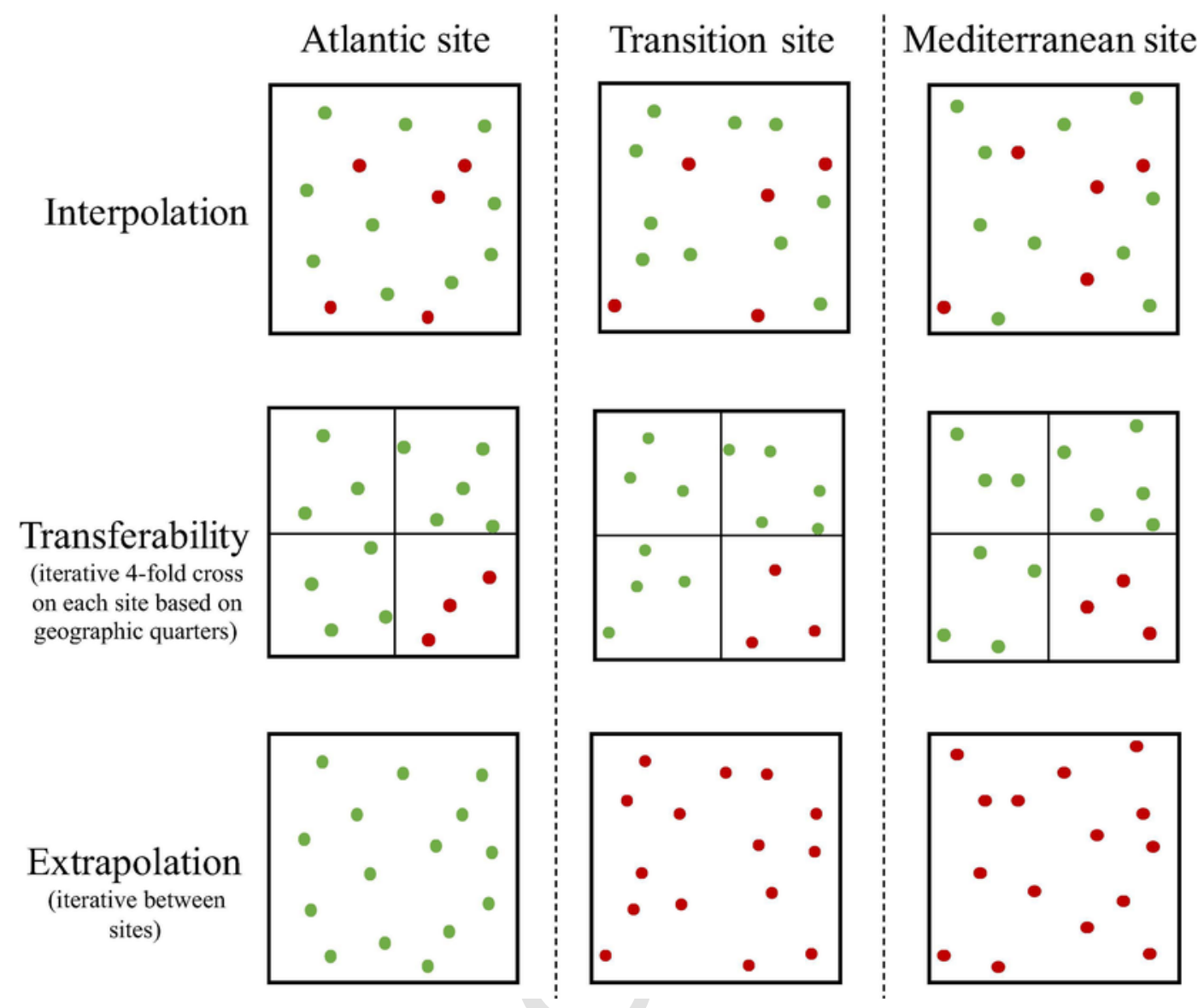

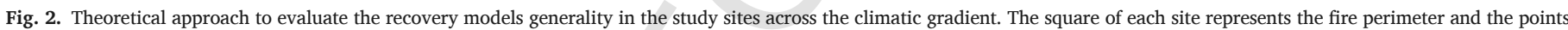
the field plots.

The extrapolation of the recovery models across the climatic gradient (Fig. 4) showed the best predictive capacity between the Transition and Mediterranean sites in both directions, with errors in terms of nRMSE ranging from 6\% to 19\%. Extrapolation to and from the Atlantic site obtained the highest prediction errors (nRMSE $>30 \%$ in 11 out of 12 extrapolations). Extrapolation towards the Transition site from the other study sites showed less error than in the opposite direction. The best extrapolation results were obtained for the woody species cover model, achieving the low predictive error (nRMSE > 9\%) between the Transition and Mediterranean sites.

Pearson correlation analysis carried out between the prediction values achieved by model extrapolation and the observed field values in each study site showed the highest correlations $(r>0.7)$ when the woody species cover model was extrapolated between the Transition and Mediterranean sites (Table 3).

\section{Discussion}

4.1. Post-fire vegetation recovery tools: Importance of spectral and textural features

Post-fire management decisions and restoration actions taken by forestry managers are largely context-dependent (Taboada et al., 2017) because post-fire vegetation recovery depends on pre-fire vegetation community composition, fire regime and climatic factors of each specific site across large spatial scales (Puig-Gironès et al., 2017). The search for new tools that may facilitate decision-making and reduce field data gathering efforts in forest management has been one of the most important aspects in recent years (Wulder et al., 2005; Mohammadi et al., 2011; Meng et al., 2016), since most of management decisions require accurate data at short-term to be applied (Schmidt et al., 2018). For that reason, these tools should allow the transfer of predictive relations from the information obtained in different geographical or climatic contexts (Foody et al., 2003; Cutler et al., 2012).

Our results showed that spectral indices and textural features derived from fine-grained satellite imagery were good predictors of vegetation recovery in fire-prone pine ecosystems across an Atlantic-Transition-Mediterranean climatic gradient. Texture features provided the greatest model contribution in the estimation of recovery variables. In these fire-prone ecosystems, fire promotes heterogeneous vegetation recovery patterns (Schoennagel et al., 2008) that can be better detected through texture features (Wood et al., 2012) accounting for discrete pixel values and their spatial adjacency relationships (Gu et al., 2013), than by other satellite products such as spectral indices. In this sense, other authors such as Lu (2007), Ozdemir and Karnieli (2011), Sarker and Nichol (2011) or Eckert (2012) also found that under heterogeneous vegetation structure, texture features were more correlated with canopy metrics than spectral indices.

Among the considered recovery variables, the density of pine seedlings was satisfactorily explained only in the Transition site across the climatic gradient. Pinus pinaster population in the Transition site presents an intensive seedling recruitment after fire (Tapias et al., 2001; Tapias et al., 2004; Calvo et al., 2013) due to its high level of 

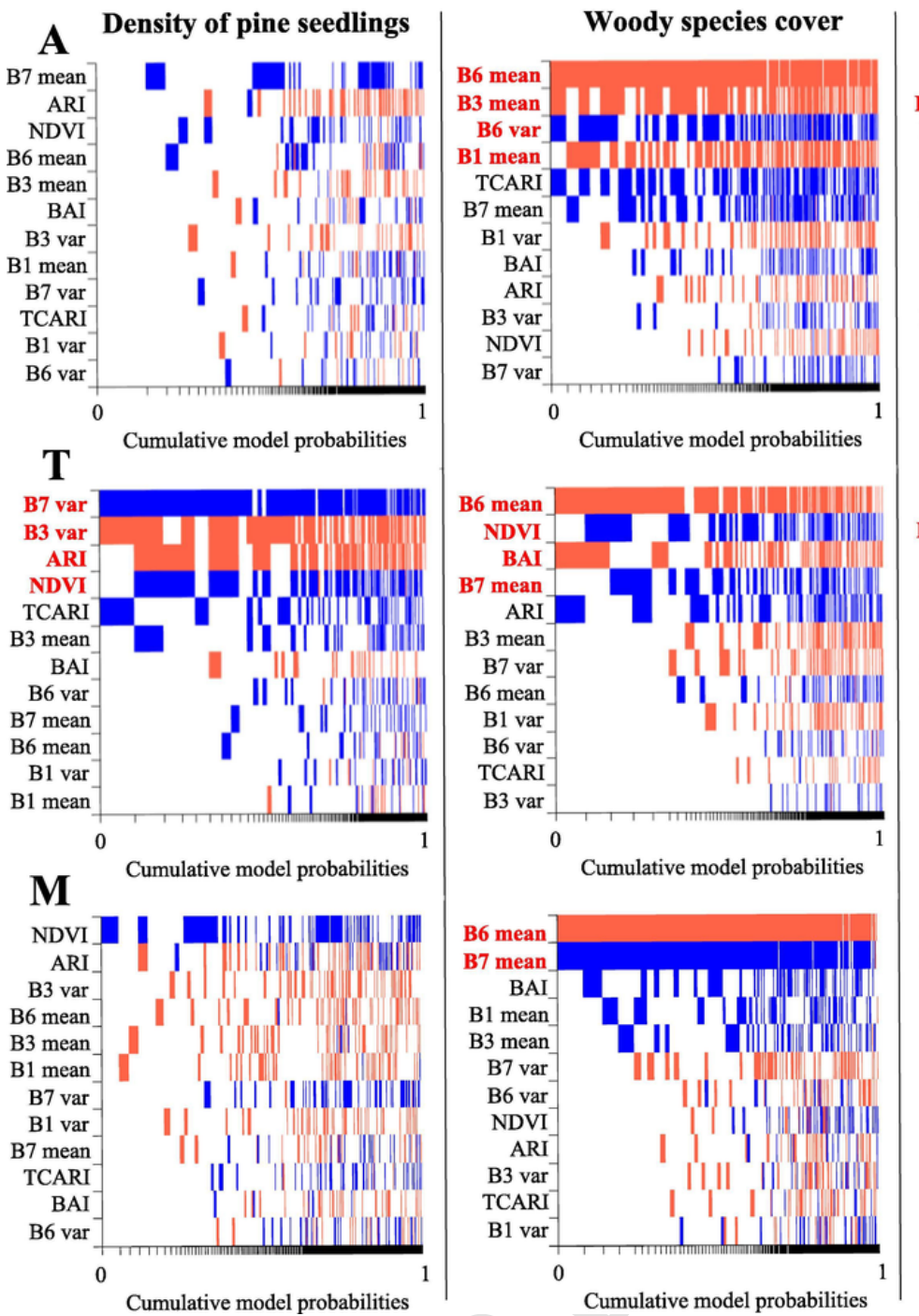

Dead plant material cover
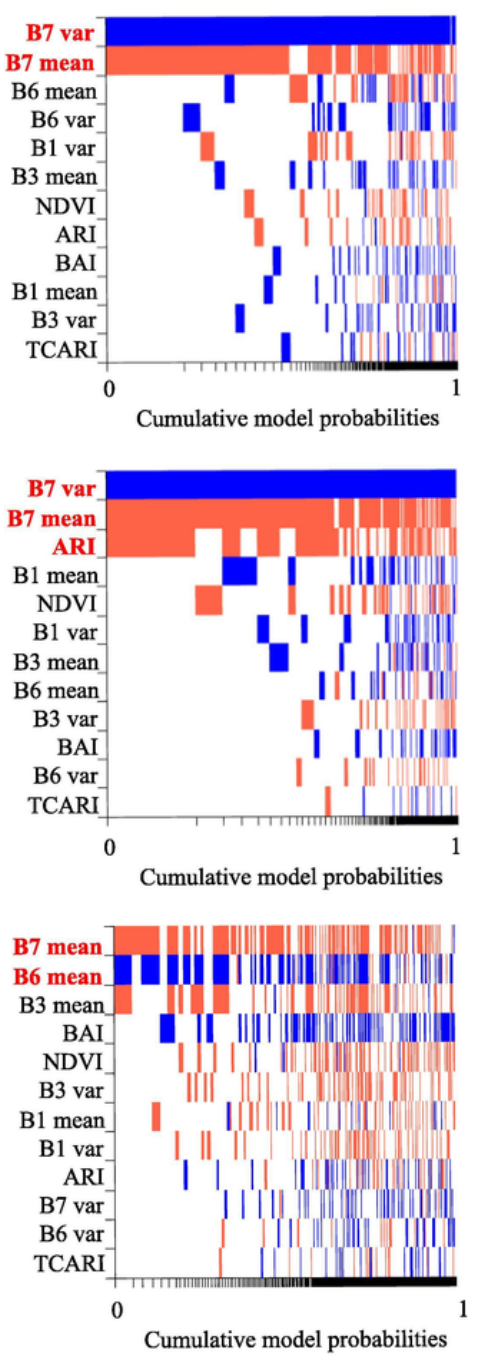

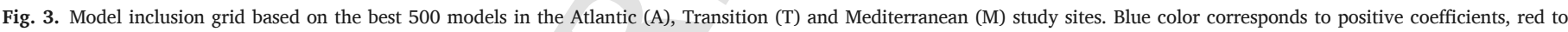

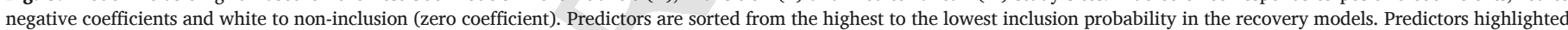

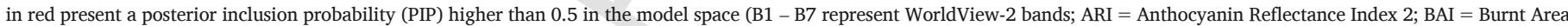

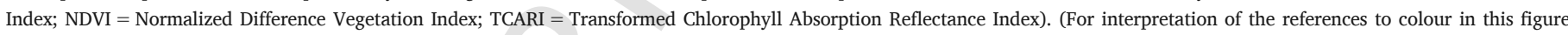
legend, the reader is referred to the web version of this article.)

Table 2

Model interpolation performance (nRMSE) and transferability performance (mean $\mathrm{nRMSE} \pm \mathrm{SD}$ of the geographic 4-fold cross-validation) for the three study sites.

\begin{tabular}{lllll}
\hline & nRMSE & & \\
& Interpolation & Transferability & \\
\hline Atlantic site & & & & \\
\hline density of pine seedlings & $24.26 \%$ & $34.67 \%$ & \pm & $25.00 \%$ \\
woody species cover & $20.05 \%$ & $24.09 \%$ & \pm & $7.34 \%$ \\
dead plant material cover & $23.88 \%$ & $28.88 \%$ & \pm & $6.08 \%$ \\
Transition site & & & & \\
density of pine seedlings & $12.01 \%$ & $16.63 \%$ & \pm & $2.91 \%$ \\
woody species cover & $8.87 \%$ & $15.83 \%$ & \pm & $1.69 \%$ \\
dead plant material cover & $14.63 \%$ & $16.40 \%$ & \pm & $1.72 \%$ \\
Mediterranean site & & & & \\
density of pine seedlings & $18.49 \%$ & $28.49 \%$ & \pm & $10.17 \%$ \\
woody species cover & $6.02 \%$ & $21.62 \%$ & \pm & $5.13 \%$ \\
dead plant material cover & $17.30 \%$ & $29.91 \%$ & \pm & $5.93 \%$ \\
\hline
\end{tabular}

serotiny (Calvo et al., 2016; Taboada et al., 2017) and early flowering in comparison with the other two study sites (Tapias et al., 2004). Therefore, seedling recruitment in the Transition site was very high in relation to that in the Atlantic and Mediterranean sites. The higher surface reflectance contribution of pine seedlings in the field plots of the Transition site could explain the population recovery in contrast to the Atlantic and Mediterranean sites (Viedma et al., 2012).

Woody species cover was successfully modeled in the three sites across the climatic gradient, using texture predictors derived from WorldView-2 imagery. Specifically, red edge texture had the highest model contribution in all cases. Although reflectance values depend on the vegetation canopy structure (Middleton, 1991) and the sun angle (Mänd et al, 2010), both varying among study sites, features derived from the red edge region of the spectrum are insensitive to these variations (Sims and Gamon, 2002). Indeed, this region is more efficient than others for differentiating soil background and vegetation spectral characteristics (Schumacher et al., 2016), as well as minimizing atmospheric effects (Mutanga et al., 2012).

Discrimination between dead plant material cover and photosynthetic vegetation was successfully achieved through the texture fea- 


\section{Atlantic Transition Mediterranean}
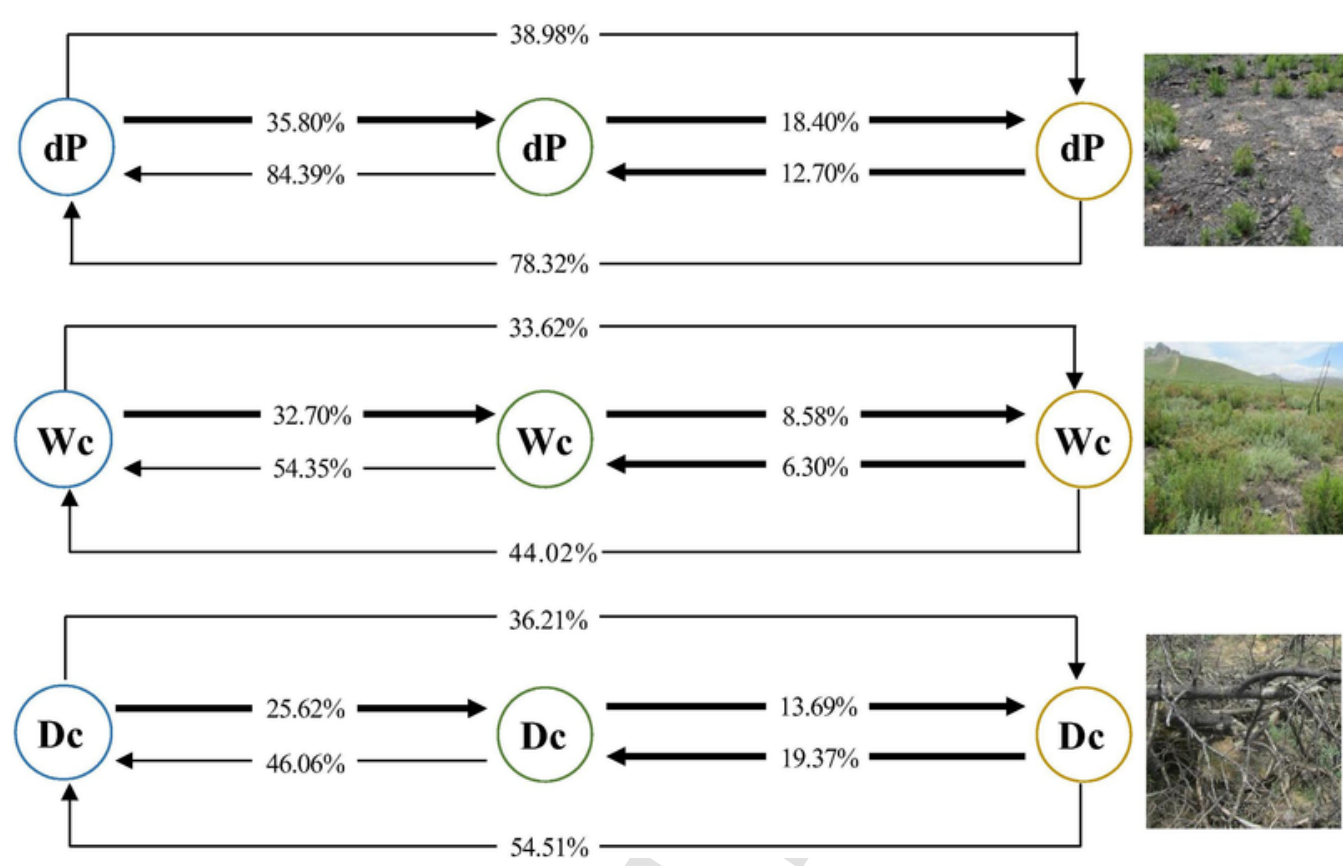

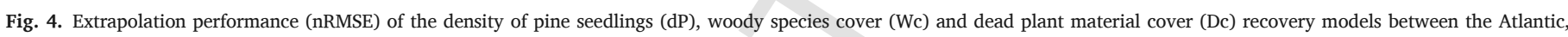
Transition and Mediterranean sites. The thickest arrows correspond to extrapolations with an error lower than $40 \%$ in terms of nRMSE.

Table 3

Bivariate Pearson correlations between prediction values achieved by model extrapolation and observed field values in each study site for the three response variables ( $\mathrm{dP}=$ density of pine seedlings; $\mathrm{Wc}=$ woody species cover; Dc = dead plant material cover).

\begin{tabular}{lllllll}
\hline $\begin{array}{l}\text { Pearson } \\
\text { correlation (r) }\end{array}$ & \multicolumn{2}{l}{ Atlantic site $(A)$} & \multicolumn{2}{l}{ Transition site $(T)$} & \multicolumn{2}{l}{$\begin{array}{l}\text { Mediterranean site } \\
(M)\end{array}$} \\
\hline & $\begin{array}{l}\text { From } \\
\text { T }\end{array}$ & $\begin{array}{l}\text { From } \\
\text { M }\end{array}$ & $\begin{array}{l}\text { From } \\
\text { A }\end{array}$ & $\begin{array}{l}\text { From } \\
\text { M }\end{array}$ & $\begin{array}{l}\text { From } \\
\text { A }\end{array}$ & $\begin{array}{l}\text { From } \\
\text { T }\end{array}$ \\
\hline dP & 0.0399 & 0.1026 & 0.0997 & 0.2794 & 0.0445 & 0.2437 \\
Wc & 0.2926 & 0.2375 & 0.5314 & 0.7327 & 0.5479 & 0.7878 \\
Dc & 0.1369 & 0.1915 & 0.3529 & 0.3900 & 0.2819 & 0.5580 \\
\hline
\end{tabular}

tures computed from the NIR region of the spectrum in the three study sites. This result was consistent with the achievements of other authors (Lasaponara, 2006; Veraverbeke et al., 2011) that also found a high discriminatory capability in this spectral region because of the lower NIR reflectance of burned vegetation in comparison with photosynthetic vegetation (Schepers et al., 2014).

In addition to assess the performance of post-fire recovery models independently in burned areas with different climatic conditions, it is useful for land management purposes to evaluate the spatial generality of models developed in one site to predict vegetation variables in other sites (Cutler et al., 2012). The implementation of remote sensing-based recovery models applicable to other contexts is a major challenge at the present time in areas with high spatial variability (Tsalyuk et al., 2017).

\subsection{Interpolation, transferability and extrapolation}

Our results confirm the hypothesis that the spatial interpolation of vegetation models showed better performance than spatial transferability within each study site, with spatial extrapolation achieving a lower performance than the other two approaches. These results were expected because the full range of environmental factors in different regions across the climatic gradient extend beyond the range of model calibration data within each region (Thuiller et al., 2004; Tsalyuk et al., 2017; Jiménez-Alfaro et al., 2018). Moreover, data partitioning by means of geographic criteria accomplished in transferability and extrapolation approaches would lead to an inferior model performance due to non-stationary responses of vegetation in the distinct areas considered for model calibration and validation (Osborne and Suárez-Seoane, 2002). On the contrary, non-stationary responses are not expected to impact the interpolation approach because the modeled relationships are relatively constant within each study site.

We achieved the highest performance in the model transferability approach within the Atlantic and Transition sites. The lower performance of this approach in the Mediterranean site was probably due to the stronger variation in the environmental factors and, therefore, in the vegetation community structure within the geographic quadrants. Spatial data partitioning in geographic quadrants would account for local variation within each quadrant in the model calibration step, being expected non-stationary responses between quadrants in the Mediterranean site given its environmental heterogeneity (Unwin and Unwin, 1998). In this sense, model calibration data in this study site would incorporate less heterogeneity in the environmental factors (Archibald and Scholes, 2007), giving less accurate model predictions (Suárez-Seoane et al., 2014; Jiménez-Alfaro et al., 2018). 
The spatial extrapolation of recovery models across regions using different satellite scenes, despite being a complicated approach (Woodcock et al., 2001), showed encouraging results. Extrapolation between the Transition and Mediterranean sites in both directions exhibited a small error, in line with the study conducted by Tsalyuk et al. (2017) in the savanna ecosystems. However, extrapolation to and from the Atlantic site obtained weaker results. This could be due to the ecosystem characteristics of this site in comparison with the Transition and Mediterranean sites, these two ecosystems being more similar in their global structure and function, and therefore, in their spectral characteristics (Cutler et al., 2012). The Atlantic site is located in a typical coastline ecosystem with a large outcrop of granitic boulders and sparse vegetation canopy. Meanwhile, the Transition and Mediterranean sites have a more similar and homogeneous canopy structure, although the plant community and, therefore, the species composition, differ widely between these two sites. In line with our initial hypothesis, spatial extrapolation to the Transition site produced better results than in the opposite direction (i.e. from the Transition site to the Atlantic and Mediterranean sites). This may be attributable to the more homogeneous landscape in the Transition site, probably due to the lower fire recurrence in comparison with the other two sites (Fernández-Manso et al., 2015). Models trained in more heterogeneous landscapes would capture more variability in the environmental factors and, therefore, they would be able to predict better vegetation parameters in other sites with a narrower environmental variation (Suárez-Seoane et al., 2014; Tsalyuk et al., 2017).

This study demonstrates the potential of fine-grained satellite imagery to conduct post-fire recovery models that are generalizable within and between different burned ecosystems across a climatic gradient. This remote sensing tool would allow land managers to reduce extensive field-sampling campaigns to monitor vegetation recovery in burned sites whose structure and function do not differ significantly from previously modeled sites. However, further research is needed to enhance the generality and applicability of recovery models to areas with greater variability in vegetation horizontal and vertical structure by exploring other remote sensing products.

\section{Conclusions}

1. Fine-grained multispectral imagery was an appropriate tool to successfully predict vegetation recovery in fire-prone pine ecosystems along an Atlantic-Transition-Mediterranean climatic gradient.

2. Texture features computed from WorldView-2 imagery provided a suitable estimation of post-fire vegetation recovery (density of pine seedlings, woody species cover) and dead plant material cover under different climatic conditions.

3. Post-fire recovery models showed a high spatial applicability across burned areas with different climatic conditions, which may present important implications for land management purposes.

4. The model interpolation approach achieved a high performance because the modeled relationships were relatively constant within each study site and vegetation non-stationary responses were not expected. The transferability approach achieved a better performance in the Atlantic and Transition sites, in contrast to the Mediterranean site. In the latter case, the stronger variation in the environmental factors within the geographic quadrants and, therefore, the possibility of non-stationary responses could lead to truncation in model calibration.

5. Model extrapolation between the Transition and Mediterranean sites in both directions exhibited an error lower than $20 \%$. Both study sites have a similar and homogeneous canopy structure, although the plant community differs widely between these two sites. Owing to the similar structure and function of these ecosystems, they have closer spectral characteristics in comparison with the Atlantic site, where extrapolation approach gave the weakest results.

6. The modeling approach followed in this study would allow land managers to evaluate post-fire vegetation recovery in burned sites across climatic gradients with high reliability.

\section{Acknowledgements}

This study was financially supported by the Spanish Ministry of Economy and Competitiveness, and the European Regional Development Fund (ERDF), in the framework of the GESFIRE (AGL2013-48189-C2-1-R) and FIRESEVES (AGL2017-86075-C2-1-R) projects; and by the Regional Government of Castilla and León in the framework of the FIRECYL (LE033U14) and SEFIRECYL (LE001P17) projects. J.M. Fernández-Guisuraga is supported by a predoctoral fellowship from the Spanish Ministry of Education (FPU16/03070).

\section{Declarations of interest}

None.

\section{References}

Archibald, S., Scholes, R.J., 2007. Leaf green-up in a semi-arid African savanna - separating tree and grass responses to environmental cues. J. Veg. Sci. 18, 583-594.

Austin, M.P., 2002. Spatial prediction of species distribution: an interface between ecological theory and statistical modelling. Ecol. Model. 157, 101-118.

Barbieri, M.M., Berger, J.O., 2003. Optimal predictive model selection. Ann. Statist. 32, 870-897.

Beaty, R.M., Taylor, A.H., 2001. Spatial and temporal variation of fire regimes in a mixed conifer forest landscape, Southern Cascades, California. USA. J. Biogeogr. 28, 955-966.

Bento-Gonçalves, A., Vieira, A., Úbeda, X., Martin, D., 2012. Fire and soils: key concepts and recent advances. Geoderma. 191, 3-13.

Berk, A., Anderson, G.P., Bernstein, L.S., Acharya, P.K., Dothe, H., Matthew, M.W., Adler-Golden, S.M., Chetwyn, J.H., Richtsmeier, S.C., Pukall, B., Allred, C.L., Jeong, L.S., Hoke, M.L., 1999. MODTRAN4 radiative transfer modeling for atmospheric correction. Proc. SPIE. 3756, 348-353.

Bond, W.J., Woodward, F.I., Midgley, G.F., 2005. The global distribution of ecosystems in a world without fire. New Phytol. 165, 525-537.

Brunsdon, C., Fotheringham, A.S., Charlton, M.E., 1996. Geographically weighted regression: a method for exploring spatial nonstationarity. Geogr. Anal. 28, 281-298.

Buchhorn, M., Walker, D.A., Heim, B., Raynolds, M.K., Epstein, H.E., Schwieder, M., 2013. Ground-based hyperspectral characterization of Alaska Tundra vegetation along environmental gradients. Remote Sens. 5, 3971-4005.

Buchhorn, M., 2014. Ground-based hyperspectral and spectro-directional reflectance characterization of Arctic tundra vegetation communities : field spectroscopy and field spectro-goniometry of Siberian and Alaskan tundra in preparation of the EnMAP satellite mission. $\mathrm{PhD}$ thesis University of Potsdam.

Calvo, L., Santalla, S., Valbuena, L., Marcos, E., Tárrega, R., Luis-Calabuig, E., 2008. Post-fire natural regeneration of a Pinus pinaster forest in NW Spain. Plant Ecol. 197, $81-90$.

Calvo, L., Torres, O., Valbuena, L., Luis, E., 2013. Recruitment and early growth of Pinus pinaster seedlings over five years after a wildfire in NW Spain. Forest Syst. 22, $582-586$.

Calvo, L., Hernández, V., Valbuena, L., Taboada, A., 2016. Provenance and seed mass determine seed tolerance to high temperatures associated to forest fires in Pinus pinaster. Ann. Forest Sci. 73, 381-391.

CEAM, 2012. http://www.ceam.es/GVAceam/ceam_val/home.htm (accessed in 10 May 2018).

Chen, D., Stow, D.A., Gong, P., 2004. Examining the effect of spatial resolution and texture window size on classification accuracy: an urban environment case. Int. J. Remote Sens. 25, 1-16

Chu, T., Guo, X., Takeda, K., 2016. Remote sensing approach to detect post-fire vegetation regrowth in Siberian boreal larch forest. Ecol. Indic. 62, 32-46.

Chuvieco, E., Pilar-Martin, M., Palacios, A., 2002. Assessment of different spectral indices in the red-near-infrared spectral domain for burned land discrimination. Remote Sens. Environ. 112, 2381-2396.

Chuvieco, E., Cocero, D., Riaño, D., Martin, P., Martínez-Vega, J., de la Riva, J., Pérez, F., 2004. Combining NDVI and surface temperature for the estimation of live fuel moisture content in forest fire danger rating. Remote Sens. Environ. 92, 322-331.

Chuvieco, E., Kasischke, E.S., 2007. Remote sensing information for fire management and fire effects assessment. J. Geophys. Res. 112, G01S90.

Cutler, M., Boyd, D., Foody, G., Vetrivel, A., 2012. Estimating tropical forest biomass with a combination of SAR image texture and Landsat TM data: an assessment of predictions between regions. ISPRS J. Photogramm. 70, 66-77.

DigitalGlobe, 2010. http://global.digitalglobe.com (accessed in 07 January 2016).

Doblas-Miranda, E., Alonso, R., Arnan, X., Bermejo, V., Brotons, L., de las Heras, J., Estiarte, M., Hódar, J.A., Llorens, P., Lloret, F., López-Serrano, F.R., Martínez-Vilalta, J., Moya, D., Peñuelas, J., Pino, J., Rodrigo, A., Roura-Pascual, N., Valladares, F., Vilà, M., Zamora, R., Retana, J., 2017. A review of the combination among global 
change factors in forests, shrublands and pastures of the Mediterranean Region: beyond drought effects. Glob. Planet. Chang. 148, 42-54.

Eckert, S., 2012. Improved forest biomass and carbon estimations using texture measures from WorldView-2 satellite data. Remote Sens. 4, 810-829.

Eicher, T., Papageorgiou, C., Raftery, A., 2009. Default priors and predictive performance in Bayesian model averaging, with application to growth determinants. J. Appl. Econom. 26, 30-55.

Esposito, G., Matano, F., Molisso, F., Ruoppolo, G., Di Benedetto, A., Sacchi, M., 2017. Post-fire erosion response in a watershed mantled by volcaniclastic deposits, Sarno Mountains, Southern Italy. Catena. 152, 227-241.

Fernandes, P.M., Rigolot, E., 2007. The fire ecology and management of maritime pine (Pinus pinaster Ait.). Forest Ecol. Manag. 241, 1-13.

Fernández, C., Ley, E., Steel, M.F., 2001. Benchmark priors for Bayesian model averaging. J. Econometrics. 100, 381-427.

Fernández-García, V., Santamarta, M., Fernández-Manso, A., Quintano, C., Marcos, E., Calvo, L., 2018. Burn severity metrics in fire-prone pine ecosystems along a climatic gradient using Landsat imagery. Remote Sens. Environ. 206, 205-217.

Fernández-Manso, A., Fernández-García, V., Quintano, C., Marcos, E., Calvo, L., 2015. Cartografía de recurrencia-severidad en grandes incendios forestales utilizando técnicas de teledetección. In: Bustamante, J., Díaz-Delgado, R., Aragonés, D., Afán, I., García, D. (Eds.), Teledetección: Humedales y Espacios Protegidos. XVI Congreso de la Asociación Española de Teledetección, Sevilla, pp. 121-124.

Fernández-Manso, A., Quintano, C., Roberts, D.A., 2016. Burn severity influence on post-fire vegetation cover resilience from Landsat MESMA fraction images time series in Mediterranean forest ecosystems. Remote Sens. Environ. 184, 112-123.

Ferreira-Leite, F., Bento-Gonçalves, A., Vieira, A., 2011. The recurrence interval of forest fires in Cabeço da Vaca (Cabreira Mountain-northwest of Portugal). Environ. Res. 111, 215-221.

Foody, G.M., Boyd, D.S., Cutler, M.E.J., 2003. Predictive relations of tropical forest biomass from Landsat TM data and their transferability between regions. Remote Sens. Environ. 85, 463-474.

García-Morote, F.A., Martínez-García, E., Andrés-Abellán, M., Caballero, E.R., Miettinen, H., López-Serrano, F.R., 2017. Direct Seeding of Pinus halepensis Mill. for recovery of burned semi-arid forests: implications for post-fire management for improving Natural Regeneration. Forests 8, 353.

Gitelson, A., Merzlyak, M., Chivkunova, O., 2001. Optical properties and nondestructive estimation of anthocyanin content in plant leaves. Photochem. Photobiol. 71, 38-45.

Gu, Z., Ju, W., Li, L., Li, D., Liu, Y., Fan, W., 2013. Using vegetation indices and texture measures to estimate vegetation fractional coverage (VFC) of planted and natural forests in Nanjing city. China. Adv. Space Res. 51, 1186-1194.

Haboudane, D., Miller, J.R., Pattey, E., Zarco-Tejada, P.J., Strachan, I.B., 2004. Hyperspectral vegetation indices and novel algorithms for predicting green LAI of crop canopies: Modeling and validation in the context of precision agriculture. Remote Sens. Environ. 90, 337-352.

Haralick, R.M., Shanmugam, K., Dinstein, I.H., 1973. Textural features for image classification. IEEE T. Syst. Man Cyb. 3, 610-621.

Hart, S.J., Schoennagel, T., Veblen, T.T., Chapman, T.B., 2015. Area burned in the western United States is unaffected by recent mountain pine beetle outbreaks. PNAS 112, 4375-4380.

Hernandez, P.A., Graham, C.H., Master, L.L., Albert, D.L., 2006. The effect of sample size and species characteristics on performance of different species distribution modeling methods. Ecography 29, 773-785.

Hoeting, J.A., Madigan, D., Raftery, A.E., Volinsky, C.T., 1999. Bayesian model averaging: a tutorial. Stat. Sci. 14, 382-417.

Hong, H., Tsangaratos, P., Ilia, I., Liu, J., Zhu, A.-X., Xu, 2018. Applying genetic algorithms to set the optimal combination of forest fire related variables and model forest fire susceptibility based on data mining models. The case of Dayu County. China. Sci. Total Environ. 630, 1044-1056.

Jiménez-Alfaro, B., Suárez-Seoane, S., Chytrý, M., Hennekens, S.M., Willner, W., Hájek, M., Agrillo, E., Álvarez-Martínez, J.M., Bergamini, A., Brisse, H., Brunet, J., Casella, L., Dítě, D., Font, X., Gillet, F., Hájková, P., Jansen, F., Jandt, U., Kącki, Z., Lenoir, J., Rodwell, J.S., Schaminée, J.H.J., Sekulová, L., Šibík, J., Škvorc, Z., Tsiripidis, I., 2018. Modelling the distribution and compositional variation of plant communities at the continental scale. Divers. Distrib. 24, 978-990.

Jung, M., Tautenhahn, S., Wirth, C., Kattge, J., 2013. Estimating basal area of spruce and fir in post-fire residual stands in Central Siberia using quickbird, feature selection, and random forests. Procedia Comput. Sci. 18, 2386-2395.

Lasaponara, R., 2006. Estimating spectral separability of satellite derived parameters for burned areas mapping in the Calabria region by using SPOT-Vegetation data. Ecol. Model. 196, 265-270.

Latif, Q.S., Saab, V.A., Hollenbeck, J.P., Dudley, J.G., 2016. Transferability of habitat suitability models for nesting woodpeckers associated with wildfire. Condor. 118, 766-790.

Liang, F., Paulo, R., Molina, G., Clyde, M.A., Berger, J.O., 2008. Mixtures of g Priors for Bayesian Variable Selection. J. Am. Stat. Assoc. 103, 410-423.

Liu, N., Budkewitsch, P., Treitz, P., 2017. Examining spectral reflectance features related to Arctic percent vegetation cover: Implications for hyperspectral remote sensing of Arctic tundra. Remote Sens. Environ. 192, 58-72.

Log, T., Thuestad, G., Velle, L.G., Khattri, S.K., Kleppe, G., 2017. Unmanaged heathland A fire risk in subzero temperatures?. Fire Safety J. 90, 62-71.

Lozano, F.J., Suárez-Seoane, S., de Luis-Calabuig, E., 2012. Does fire regime affect both temporal patterns and drivers of vegetation recovery in a resilient Mediterranean landscape? A remote sensing approach at two observation levels. Int. J. Wildland Fire. $21,666-679$.

Lu, D., 2007. Aboveground biomass estimation using Landsat TM data in the Brazilian Amazon. Int. J. Remote Sens. 26, 2509-2525.

Mänd, P., Hallik, L., Peñuelas, J., Nilson, T., Duce, P., Emmett, B.A., Beier, C., Estiarte, M., Garadnai, J., Kalapos, T., Schmidt, I.K., Kovács-Láng, E., Prieto, P., Tietema, A Westerveld, J.W., Kull, O., 2010. Responses of the reflect to experimental warming and drought in European shrublands along a north-south climatic gradient. Remote Sens. Environ. 114, 626-636.

Mansourian, S., Vallauri, D., Dudley, N., 2005. Forest Restoration in Landscapes: Beyond Planting Trees. Springer, New York.

Matthew, M., Adler-Golden, S., Berk, A., Felde, G., Anderson, G., Gorodetzky, D., Paswaters, S., Shippert, M., 2003. Atmospheric correction of spectral imagery: evaluation of the FLAASH algorithm with AVIRIS data. Proc. SPIE. 5093, 474-482.

Meng, J., Li, S., Wang, W., Liu, Q., Xie, S., Ma, W., 2016. Mapping forest health using spectral and textural information extracted from SPOT-5 satellite images. Remote Sens. 8 719 .

Meng, R., Wu, J., Schwager, K.L., Zhao, F., Dennison, P.E., Cook, B.D., Brewster, K., Green, T.M., Serbin, S.P., 2017. Using high spatial resolution satellite imagery to map forest burn severity across spatial scales in a Pine Barrens ecosystem. Remote Sens. Environ. 191, 95-109.

Meng, R., Wu, J., Zhao, F., Cook, B.D., Hanavan, R.P., Serbin, S.P., 2018. Measuring short-term post-fire forest recovery across a burn severity gradient in a mixed pine-oak forest using multi-sensor remote sensing techniques,. Remote Sens. Environ. 210, 282-296.

Middleton, E.M., 1991. Solar zenith angle effects on vegetation indexes in tallgrass prairie. Remote Sens. Environ. 38, 45-62.

Mitchell, J.J., Shrestha, R., Spaete, L.P., Glenn, N.F., 2015. Combining airborne hyperspectral and LiDAR data across local sites for upscaling shrubland structural information: lessons for HyspIRI. Remote Sens. Environ. 167, 98-110.

Mitri, G.H., Gitas, I.Z., 2013. Mapping post-fire forest regeneration and vegetation recovery using a combination of very high spatial resolution and hyperspectral satellite imagery. Int. J. Appl. Earth Obs. 20, 60-66.

Mohammadi, J., Shataee, S., Babanezhad, M., 2011. Estimation of forest stand volume, tree density and biodiversity using Landsat ETM + Data, comparison of linear and regression tree analyses. Procedia Environ. Sci. 7, 299-304.

Mutanga, O., Adam, E., Cho, M.A., 2012. High density biomass estimation for wetland vegetation using WorldView-2 imagery and random forest regression algorithm. Int J. Appl. Earth Obs. 18, 399-406.

Ninyerola, M., Pons, X., Roure, J.M., 2005. Atlas Climático Digital de la Península Ibérica. Universidad Autónoma de Barcelona, Metodología y aplicaciones en bioclimatología y geobotánica.

Nunes, A.N., Lourenço, L., Castro-Meira, A.C., 2016. Exploring spatial patterns and drivers of forest fires in Portugal (1980-2014). Sci. Total Environ. 573, 1190-1202.

Osborne, P.E., Suárez-Seoane, S., 2002. Should data be partitioned spatially before building large-scale distribution models?. Ecol. Model. 157, 249-259.

Osborne, P.E., Foody, G.M., Suárez-Seoane, S., 2007. Non-stationarity and local approaches to modelling the distributions of wildlife. Div. Distrib. 13, 313-323.

Ozdemir, I., Karnieli, A., 2011. Predicting forest structural parameters using the image texture derived from WorldView-2 multispectral imagery in a dryland forest. Israel. Int. J. Appl. Earth Obs. 13, 701-710.

Pausas, J., Llovet, J., Rodrigo, A., Vallejo, R., 2008. Are wildfires a disaster in the Mediterranean basin? - A review. Int. J. Wildland Fire. 17, 713-723.

Pausas, J., Keely, J.E., 2009. A burning story: the role of fire in the history of life. Bioscience 59, 593-601.

Pereg, L., Mataix-Solera, J., McMillan, M., García-Orenes, F., 2018. The impact of post-fire salvage logging on microbial nitrogen cyclers in Mediterranean forest soil. Sci. Total Environ. 619-620, 1079-1087.

Pereira, P., Francos, M., Brevik, E.C., Ubeda, X., Bogunovic, I., 2018. Post-fire soil management. Curr. Opin. Environ. Sci. Health. 5, 26-32.

Perrault, L.M., Yager, E.M., Aalto, R., 2017. Effects of gradient, distance, curvature and aspect on steep burned and unburned hillslope soil erosion and deposition. Earth Surf. Proc. Land. 42, 1033-1048.

Peterson, T.A., Papeş, M., Eaton, M., 2007. Transferability and model evaluation in ecological niche modeling: a comparison of GARP and Maxent. Ecography 30, 550-560.

Pinto, C., Viegas, D., Almeida, M., Raposo, J., 2017. Fire whirls in forest fires: an experimental analysis. Fire Safety J. 87, 37-48.

$\mathrm{Pu}$, R., Cheng, J., 2015. Mapping forest leaf area index using reflectance and textural information derived from WorldView-2 imagery in a mixed natural forest area in Florida. US. Int. J. Appl. Earth Obs. 42, 11-23.

Puig-Gironès, R., Brotons, L., Pons, P., 2017. Aridity influences the recovery of vegetation and shrubland birds after wildfire. PLoS ONE. 12, e0173599.

Quintano, C., Fernández-Manso, A., Calvo, L., Marcos, E., Valbuena, L., 2015. Land surface temperature as potential indicator of burn severity in forest Mediterranean ecosystems. Int. J. Appl. Earth Obs. 36, 1-12.

Core Team, R., 2017. R: A language and environment for statistical computing. R Foundation for Statistical Computing, Vienna, Austria, http://www.R-project.org/.

Radosavljevic, A., Anderson, R.P., 2014. Making better Maxent models of species distributions: complexity, overfitting and evaluation. J. Biogeogr. 41, 629-643.

Raftery, A.E., Madigan, D., Hoeting, J.A., 1997. Bayesian model averaging for linear regression models. J. Am. Stat. Assoc. 92, 179-191.

Roach, N.S., Hunter, E.A., Nibbelink, N.P., Barrett, K., 2017. Poor transferability of a distribution model for a widespread coastal marsh bird in the southeastern United States. Ecosphere. 8, e01715.

Rodríguez-Lado, 2012. Servidor de mapas de propiedades de suelos de Galicia. http://rgis cesga.es/index.html (accessed in 10 May 2018).

Rouse, J., Haas, R., Schell, J., Deering, D., 1973. Monitoring vegetation systems in the great plains with ERTS. Third ERTS Symposium. 1, 309-317.

Sarker, L.R., Nichol, J.E., 2011. Improved forest biomass estimates using ALOS AVNIR-2 texture indices. Remote Sens. Environ. 115, 968-977.

Schepers, L., Haest, B., Veraverbeke, S., Spanhove, T., Vanden-Borre, J., Goossens, R. 2014. Burned area detection and burn severity assessment of a heathland fire in Belgium using Airborne Imaging Spectroscopy (APEX). Remote Sens. 6, 1803-1826.

Schmeer, S.R., Kampf, S.K., MacDonald, L.H., Hewitt, J., Wilson, C., 2018. Empirical models of annual post-fire erosion on mulched and unmulched hillslopes. Catena 163 (2018), 276-287. 
Schmidt, I.B., Moura, L.C., Ferreira, M.C., Eloy, L., Sampaio, A.B., Dias, P.A., Berlinck, C.N., 2018. Fire management in the Brazilian savanna: first steps and the way forward. J. Appl. Ecol. 55, 2094-2101.

Schoennagel, T., Smithwick, A.H., Turner, M.G., 2008. Landscape heterogeneity following large fires: insights from Yellowstone National Park. USA. Int. J. Wildland Fire. 17, 742-753.

Schumacher, P., Mislimshoeva, B., Brenning, A., Zandler, H., Brandt, M., Samimi, C., Koellner, T., 2016. Do Red edge and texture attributes from high-resolution satellite data improve wood volume estimation in a semi-arid mountainous region?. Remote Sens. 8,540 .

Sevegnani, L., Uhlmann, A., de Gasper, A.L., Meyer, L., Vibrans, A.C., 2016. Climate affects the structure of mixed rain forest in southern sector of Atlantic domain in Brazil. Acta Oecol. 77, 109-117.

Shakesby, R.A., 2011. Post-wildfire soil erosion in the Mediterranean: review and future research directions. Earth-Sci. Rev. 105, 71-100.

Shamsoddini, A., Trinder, J.C., Turner, R., 2013. Pine plantation structure mapping using WorldView-2 multispectral image. Int. J. Remote Sens. 34, 3986-4007.

Sims, D.A., Gamon, J.A., 2002. Relationships between leaf pigment content and spectral reflectance across a wide range of species, leaf structures and developmental stages. Remote Sens. Environ. 81, 337-354.

Solans-Vila, J.P., Barbosa, P., 2010. Post-fire vegetation regrowth detection in the Deiva Marina region (Liguria-Italy) using Landsat TM and ETM + data. Ecol. Model. 221, $75-84$.

Suárez-Seoane, S., Virgós, E., Terroba, O., Pardavila, X., Barea-Azcón, J.M., 2014. Scaling of species distribution models across spatial resolutions and extents along a biogeographic gradient. The case of the Iberian mole Talpa occidentalis. Ecography 37, 279-292.

Sumnall, M., Peduzzi, A., Fox, T.R., Wynne, R.H., Thomas, V.A., Cook, B., 2016. Assessing the transferability of statistical predictive models for leaf area index between two airborne discrete return LiDAR sensor designs within multiple intensely managed Loblolly pine forest locations in the south-eastern USA. Remote Sens. Environ. 176, 308-319.

Sundblad, G., Harma, M., Lappalainen, A., Urho, L., Bergstrom, U., 2009. Transferability of predictive fish distribution models in two coastal systems. Estuar. Coast. Shelf S. 83, 90-96.

Taboada, A., Tárrega, R., Marcos, E., Valbuena, L., Suárez-Seoane, S., Calvo, L., 2017. Fire recurrence and emergency post-fire management influence seedling recruitment and growth by altering plant interactions in fire-prone ecosystems. Forest Ecol. Manag. 402, 63-75.

Tao, Y., Zhang, Y.-M., Downing, A., 2013. Similarity and difference in vegetation structure of three desert shrub communities under the same temperate climate but with different microhabitats. Bot. Stud. 54, 59.

Tapias, R., Gil, L., Fuentes-Utrilla, P., Pardos, J.A., 2001. Canopy seed banks in Mediterranean pines of southeastern Spain: a comparison between Pinus halepensis Mill., Pinus pinaster Ait., Pinus nigra Arn. and Pinus pinea L. J. Ecol. 89, 629-638.

Tapias, R., Climent, J., Pardos, J.A., Gil, L., 2004. Life histories of Mediterranean pines. Plant Ecol. 171, 53-68.

Tessler, N., Wittenberg, L., Greenbaum, N., 2016. Vegetation cover and species richness after recurrent forest fires in the Eastern Mediterranean ecosystem of Mount Carmel. Israel. Sci. Total Environ. 572, 1395-1402.

Thenkabail, P.S., Lyon, J.G., Huete, A., 2011. Hyperspectral Remote Sensing of Vegetation. CRC Press, Boca Ratón, Florida.
Thuiller, W., Brotons, L., Araújo, M.B., Lavorel, S., 2004. Effects of restricting environmental range of data to project current and future species distributions. Ecography. 27, $165-172$.

Tsalyuk, M., Kelly, M., Getz, W.M., 2017. Improving the prediction of African savanna vegetation variables using time series of MODIS products. ISPRS J. Photogramm. 131 77-91.

Unwin, A., Unwin, D., 1998. Exploratory spatial data analysis with local statistics. Statistician. 47, 415-421.

Veraverbeke, S., Harris, S., Hook, S., 2011. Evaluating spectral indices for burned area discrimination using MODIS/ASTER (MASTER) airborne simulator data. Remote Sens. Environ. 115, 2702-2709.

Veraverbeke, S., Gitas, I., Katagis, T., Polychronaki, A., Somers, B., Goossens, R., 2012 Assessing post-fire vegetation recovery using red-near infrared vegetation indices: Ac counting for background and vegetation variability. ISPRS J. Photogramm. 68, 28-39.

Viedma, O., Torres, I., Pérez, B., Moreno, J.M., 2012. Modeling plant species richness using reflectance and texture data derived from QuickBird in a recently burned area of Central Spain. Remote Sens. Environ. 119, 208-221.

Wenger, S.J., Isaak, D.J., Dunham, J.B., Fausch, K.D., Luce, C.H., Neville, H.M., Rieman, B.E., Young, M.K., Nagel, D.E., Horan, D.L., Chandler, G.W., 2011. Role of climate and invasive species in structuring trout distributions in the Interior Columbia Basin. Can. J. Fish. Aquat. Sci. 68, 988-1008.

Wenger, S.J., Olden, J.D., 2012. Assessing transferability of ecological models: an underappreciated aspect of statistical validation. Methods Ecol. Evol. 3, 260-267.

Whelan, R.J., 1995. The ecology of fire. Cambridge University Press, Cambridge.

Wood, E.M., Pidgeon, A.M., Radeloff, V.C., Keuler, N.S., 2012. Image texture as a remotely sensed measure of vegetation structure. Remote Sens. Environ. 121, 516-526.

Woodcock, C.E., Macomber, S.A., Pax-Lenney, M., Cohen, W.B., 2001. Monitoring large areas for forest change using Landsat: generalization across space, time and Landsat sensors. Remote Sens. Environ. 78, 194-203.

Wulder, M.A., Hall, R.J., Franklin, S.E., 2005. Remote sensing and GIS in forestry. In: Aronoff, S. (Ed.), Remote sensing for GIS managers. ESRI Press, Redlands, pp. 351-362.

Xiao, J., Moody, A., 2008. Geographical distribution of global greening trends and their climatic correlates: 1982-1998. Int. J. Remote Sens. 26, 2371-2390.

Zellner, A., 1986. On Assessing Prior Distributions and Bayesian Regression Analysis with g-Prior Distributions. In: Goel, P., Zellner, A. (Eds.), Bayesian Inference and Decision Techniques: Essays in Honor of Bruno de Finetti. Elsevier Science Publishers Inc., New York, pp. 233-243.

Zeugner, S., Feldkircher, M., 2015. Bayesian model averaging employing fixed and flexible priors: the BMS package for R. J. Stat. Softw. 68, 1-37.

Zhang, C., Xie, Z., 2012. Combining object-based texture measures with a neural network for vegetation mapping in the Everglades from hyperspectral imagery. Remote Sens. Environ. 124, 310-320.

Zhao, K., Valle, D., Popescu, S., Zhang, X., Mallick, B., 2013. Hyperspectral remote sensing of plant biochemistry using Bayesian model averaging with variable and band selection. Remote Sens. Environ. 132, 102-119.

Zhu, Z., Bi, J., Pan, Y., Ganguly, S., Anav, A., Xu, L., Samanta, A., Piao, S., Nemani, R.R., Myneni, R.B., 2013. Global data sets of vegetation leaf area index (LAI)3g and fraction of photosynthetically active radiation (FPAR) $3 g$ derived from global inventory modeling and mapping studies (GIMMS) normalized difference vegetation index (NDVI3g) for the period 1981 to 2011. Remote Sens. 5, 927-948. 